\section{Dentist creates game so that children can 'fight decay'}

A new dental game for children to create awareness about dental decay and ways to

Dentist Dr Buds has developed the game with a specialist team of game developers so that children can learn and play in a safe and fun way. The 'Rate of Decay' game has a knowledge board to learn about tooth decay, and multiple choice questions which can be answered independently or as part of the game.

The game is simple to play for young children, and parents, carers and teachers will be able to learn as well, by helping younger children with information and

The player of the game has to answer oral health-related questions. If sufficient questions are answered correctly the player is given an option to choose a weapon to kill the bacteria as they make their way to prevent it launched on 8 March 2020. multiple choice questions. destroy a set of teeth.

The gameboards change and become more interesting as the player moves to higher levels. The first three levels and all the oral health information is available free of charge.

There are also character stickers and posters to accompany the launch of the game. The game will be available as a downloadable App from Apple and Google stores.

There will be a small fee for higher levels of the game but any profit generated will be used to promote greater awareness of the 'Rate of Decay', and the importance of oral health generally in schools and online.

UK-based Dr Buds, who has practised as a dentist in a few countries both in and out of the UK, said: 'Inspired by my own experience of treating patients, this self-funded venture was initiated to raise awareness and improve the dental health of children globally. I've tapped into numerous sources of oral health information to form the central educational part of this game, but any feedback is most welcome. Indeed, any member of the dental community who would like to assist with promoting this exciting new game which has a genuine social purpose at its heart, is encouraged to contact me - I would love to hear from you. I have exciting plans for the future, which include a Rate of Decay card and board game'.

Dentists, educationalists and other interested collaborators can contact Dr Buds through the game's new website www.rateofdecay.co.uk. Any donations received will be used to print stickers and posters, which will be distributed free to the dental community and schools. Practices that would like to have bespoke stickers and posters printed should also contact Dr Buds for more information.

\section{Keep it simple with one adhesive}

Are you tired of having to use multiple dental adhesives to reach the outcomes you want?

You can meet all of your bonding needs with Scotchbond Universal adhesive from $3 \mathrm{M}$ Oral Care.

Scotchbond Universal adhesive from $3 \mathrm{M}$ bonds to the majority of dental materials including metals, composites, alloys and natural teeth, all without the need for primer. Scotchbond Universal adhesive by $3 \mathrm{M}$ doesn't require any mixing and can form a strong bond with just one coat - saving time and keeping your workflows streamlined.
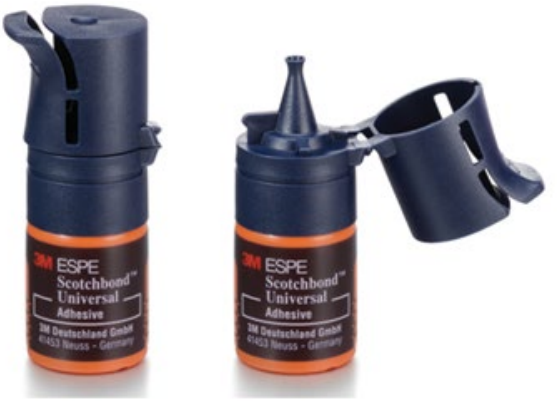

Discover more by contacting 3M Oral Care. For more information, call 0800626578 or visit www.3M.co.uk/Dental.

$3 \mathrm{M}$ and Scotchbond are trademarks of the 3M Company.

\section{Give them an aesthetic option}

We live in a world where appearance matters. So why not offer all of your patients the chance for a more naturallooking restorative option?

Monolith Full-Contour Zirconia from CosTech Dental Laboratory is a durable, aesthetic and versatile option designed specifically for NHS patients.

Available at just $£ 29.95$ per unit including delivery to and from the laboratory, this material is also available in all Vita shades from A-D, meaning that it can be used to treat a wide array of patients.

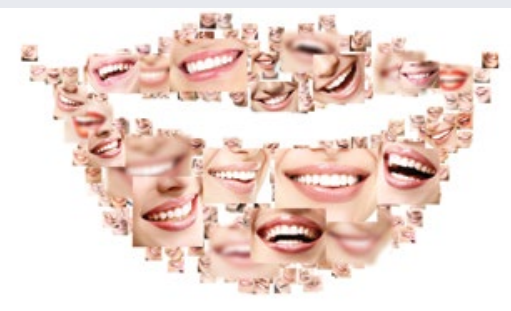

With smile aesthetics playing a key role in patients' lives, it makes sense to be able to give them a beautiful, strong restoration that blends with their natural dentition.

For more information about CosTech Dental Laboratory, visit www.costech. co.uk or call 01474320076.

\section{For safe and effective arthroscopic surgery}

Where patients require mid line treatment for TMJ disorders, finding the most minimally invasive solution is important.

Incito Medtech offers Arthroscope Systems for this reason. Using only the highest quality of materials with instruments that have been carefully designed for both surgical efficiency and patient comfort, the systems provide the tools professionals need to ensure safe and effective arthroscopic surgery.

TMJ disorders can have a massive impact on patients' lives. Where appropriate, offering as conservative a surgery as possible to correct their problems will encourage treatment acceptance and ensure they get the care they need.

For more information about the Arthroscope Systems, call Karen Joy on 07468 420496, email Karen.Joy@incitomedtech.co.uk or visit http://incitomedtech.co.uk. 